\title{
APD or CAPD: one glove does not fit all
}

\author{
Athanasios Roumeliotis ${ }^{1} \cdot$ Stefanos Roumeliotis ${ }^{1} \cdot$ Konstantinos Leivaditis $^{1} \cdot$ Marios Salmas $^{2}$. \\ Theodoros Eleftheriadis ${ }^{3} \cdot$ Vassilios Liakopoulos $^{1}$ (I)
}

Received: 12 July 2020 / Accepted: 3 October 2020 / Published online: 13 October 2020

(c) Springer Nature B.V. 2020

\begin{abstract}
The use of Automated Peritoneal Dialysis (APD) in its various forms has increased over the past few years mainly in developed countries. This could be attributed to improved cycler design, apparent lifestyle benefits and the ability to achieve adequacy and ultrafiltration targets. However, the dilemma of choosing the superior modality between APD and Continuous Ambulatory Peritoneal Dialysis (CAPD) has not yet been resolved. When it comes to fast transporters and assisted PD, APD is certainly considered the most suitable Peritoneal Dialysis (PD) modality. Improved patients' compliance, lower intraperitoneal pressure and possibly lower incidence of peritonitis have been also associated with APD. However, concerns regarding increased cost, a more rapid decline in residual renal function, inadequate sodium removal and disturbed sleep are APD's setbacks. Besides APD superiority over CAPD in fast transporters, the other medical advantages of APD still remain controversial. In any case, APD should be readily available for all patients starting PD and the most important indication for its implementation remains patient's choice.
\end{abstract}

Keywords Automated peritoneal dialysis (APD) · Continuous ambulatory peritoneal dialysis (CAPD) · Fast transporters · Patient selection

\section{Introduction}

The implementation of various forms of Automated Peritoneal Dialysis (APD) has considerably increased over the past few years. This increase can be attributed to improved cycler design, apparent lifestyle advantages and the ability to achieve adequacy and ultrafiltration targets. According to the European Renal Association/European Dialysis and Transplant Association (ERA/EDTA) database, the use of APD in Europe showed a remarkable increase in 2016. In Greece, $65 \%$ of Peritoneal Dialysis (PD) patients were on APD. This percentage varied between 40 and $60 \%$ in most

Vassilios Liakopoulos

liakopul@otenet.gr

1 Division of Nephrology and Hypertension, 1st Department of Internal Medicine, AHEPA University Hospital, School of Medicine, Aristotle University of Thessaloniki, 1, St. Kyriakidi Street, 54636 Thessaloníki, Greece

2 Department of Anatomy, School of Medicine, National and Kapodistrian University of Athens, Athens, Greece

3 Department of Nephrology, Medical School, University of Thessaly, Larissa, Greece
European countries [1]. In the United States (US), APD is the first choice for patients initiating PD since the late 90s. Considering the relatively steady overall implementation of PD, the proportion of APD has risen at the expense of Continuous Ambulatory PD (CAPD). According to the US Renal Data System (USRDS), the percentage of patients on APD has increased from 47\% in 2000 to $80 \%$ in 2015, while over the same period the total PD proportion of all dialysis patients has merely increased from 8.9 to $10 \%$ [2]. In Canada, APD accounted for $64 \%$ and $71 \%$ of patients on PD in 2009 and 2018 respectively [3]. In 2013, 64\% and 47\% of PD patients were on APD in Australia and New Zealand respectively, while in 2017 these rates had risen to $67 \%$ and $52 \%$, respectively [4]. An epidemiologic study demonstrated lower APD utilization in developing countries compared to the developed ones (15.8\% vs $42.4 \%$ of PD patients, respectively) [5]. The increased APD proportion in the developed world could be at least partially explained by the fact that patients choose APD over CAPD [6, 7], mainly because of lifestyle related issues rather than solid clinical evidence [8]. 


\section{Technique and patient survival}

The superiority of APD over CAPD on technique and/ or patient survival remains controversial. Yet, resolving this issue is challenging, since the implementation of randomized controlled trials is obviously difficult and randomized blind studies are impossible to carry out. The existing studies reveal conflicting results.

The majority of publications study both technique and patient survival rates when comparing APD to CAPD and the findings remain controversial. The US study of Guo and Mujais based on the Baxter Healthcare Corporation On-Call ${ }^{\mathrm{TM}}$ system, included approximately 30,000 patients and showed better technique survival rates for APD patients during the first 12 months [9]. In a later study that included over 40,000 patients, Mujais and Story reported that APD is a key factor in technique success with a relative risk of 0.845 compared to CAPD [10]. Sun et al. specifically studied patients younger than 65 years of age and suggested that APD probably offers increased technique survival [11]. A study from Thailand with a 10-year follow-up of 121 patients, a number rarely seen in randomized controlled studies showed an improved technique survival for those on APD [12]. Yet, a meta-analysis of just three randomized controlled trials comparing CAPD to APD included 139 patients and did not show any benefit in favor of any of the two modalities in terms of technique survival [13]. A Brazilian study included 2890 incident patients using propensity-score matching and after a 5-year follow-up showed no advantage for APD patients regarding technique failure [14]. On the other hand, some studies showed a reduced technique survival for APD patients. A 10-year propensity-score matched cohort study from Taiwan enrolling more than 4500 patients from 2001 to 2010 revealed a significantly lower technique survival for APD. The disadvantage was evident only for the subperiod between 2005 and 2007 during which patients were massively enrolled in APD, mainly due to changes in the security payment system and potential physician bias [15]. Although a previous study from the ANZDATA (Australia and New Zealand Dialysis and Transplant Registry) including 4128 patients showed similar results regarding technique failure between the two modalities, a recent similar publication revealed a disadvantage for APD regarding technique survival at 1 year. Interestingly, the size of the PD center was also a determinant for technique failure, with smaller and mainly medium-sized centers (following between 5 and 20 incident PD patients per year) having the worst results [16]. We have recently stated that small PD centers with limited experience reserve icodextrin dialysis solution in APD patients as a salvage option only for those with established ultrafiltration failure. In our opinion, the limited or delayed use of icodextrin may compromise APD efficiency and technique survival [17]. Indeed, the use of icodextrin for the long day dwell in APD patients has been proven advantageous mainly in fast transporters. In a study performed in China with 6904 incident patients divided into three 4-year intervals, both APD and icodextrin have been associated with increased technique survival [18].

In terms of survival rates, the US study of Guo and Mujais, with approximately 30,000 patients showed better patient survival rates for APD compared to CAPD patients during the first 12 months [9]. The study of the younger patients (age off less than 65) also revealed that APD probably offers increased patient survival [11]. In addition, the Brazilian study showed a $40 \%$ increased survival probability for APD patients, in terms of cardiovascular and overall mortality [14]. Similarly, the study by Wang et al. found a beneficial effect of both APD and use of icodextrin on survival rates [18]. A study with a 10-year follow-up from Kuwait failed to show any mortality difference between the two modalities. However, when patients who were free of peritonitis were separately analyzed, these on APD had a clearly better survival [19]. A recent large Chinese observational study from the Baxter Healthcare (China) Investment Co. Ltd Patient Support Program Database followed 100,351 patients from 1178 centers between 2005 and 2015 [20]. Out of these patients, only 368 received APD at some time. APD was associated with an overall lower adjusted mortality risk compared to CAPD, but the study suffered from two important limitations: selection bias and residual confounding. Despite the positive influence of APD on survival rates, the aforementioned meta-analysis of three randomized controlled trials did not show any benefit in favor of any of the two modalities in terms of mortality [12]. Even more, some studies showed a reduced patient survival for APD. The previously mentioned study from Taiwan revealed a significantly lower patient survival rate for APD. Of note, the disadvantage was evident only in the second sub-period, during which patients were massively enrolled in APD, mainly due to changes in the security payment system and potential physician bias [15].

\section{APD and fast transporters}

According to the European Best Practice Guidelines (EBPG) there are three major indications for APD implementation: patient choice, avoidance of increased intraperitoneal pressure and failure to achieve ultrafiltration targets and clearance adequacy, particularly in fast transporters [21]. Towards the same direction International Society of Peritoneal Dialysis, ad hoc Committee on Ultrafiltration Management in Peritoneal Dialysis, suggests APD use in the occurrence of ultrafiltration failure in fast transporters [22]. High 
peritoneal membrane permeability has been associated with poor technique and patient survival in PD [23-25]. Nevertheless, several studies have shown that APD could be of benefit in fast transporters. European APD Outcome Study (EAPOS) has shown that baseline membrane transport status is not associated with ultrafiltration achieved within the first year of PD and does not affect technique survival [26]. In a publication from the ANZDATA Registry, poor prognosis has been associated with fast transporters only on CAPD and not on APD [25]. In another study from Toronto, fast peritoneal membrane transport status was not a prognostic factor for poor patient and technique survival for APD patients irrespective of the use of icodextrin [27]. Another study of 4128 patients moved one step further and showed that APD leads to better survival of fast transporters, while low transporters on APD suffer from higher mortality. In the same study, there was no significant difference in technique survival between APD and CAPD [28]. Thus, it is since some years recognized that the initial concern regarding the clinical outcome of APD implementation in fast transporters with or without the use of icodextrin seems to belong to the past [29].

\section{Peritonitis}

One of the main issues in interpreting studies on the incidence of peritonitis is the different ways they report peritonitis episodes. Among others, authors report peritonitis rates as episodes per year, number of patient-months per episode, percentage of peritonitis free patients and time to first peritonitis episode. This renders the evaluation and comparison of the studies a difficult task, leads to a certain degree of confusion [30] and has forced the International Society of PD in the 2016 peritonitis guidelines to recommend that peritonitis rates to be stated as episodes per year [31]. APD implementation requires one connection and one disconnection on a daily basis. Correspondingly, an average of 4 connections and 4 disconnections are required for CAPD. It is obvious that the smaller number of maneuvers required for APD could lead to a significant reduction of peritonitis incidence. Additionally, leukocyte function improves during a long dwell of PD dialysate [32], which is the case in PD dialysate daily retention in continuous cyclic PD (CCPD). Moreover, the peritoneal mesothelial cells exhibit improved function after several hours of peritoneal membrane rest [33], which resembles "dry" daytime in nocturnal intermittent PD (NIPD). Nevertheless, the delay in peritonitis diagnosis in APD raises several concerns, while the results of relevant studies remain contradictory. Older retrospective studies have shown favorable results for APD [34, 35], other studies for CAPD [36, 37], while similar results have been also reported in studies comparing the two modalities [38].
A large prospective non-randomized study of 328 patients showed similar rates of peritonitis and exit site infection between the two modalities [39]. However, a smaller study of 20 patients showed lower peritonitis rates for APD [40]. A publication from Mexico including 237 patients reported significantly lower peritonitis rates for APD [41]. In this study, the relative risk for the first peritonitis episode was 0.68 in APD compared to CAPD. The 2007 meta-analysis indicated a similar relative risk for peritonitis between the two modalities, but a significantly lower peritonitis rate for APD [13]. As noted before, this meta-analysis was based on just three randomized controlled trials, only two of which analyzed peritonitis rates while one of them reported only three peritonitis episodes. Therefore, its results were essentially based on one study which included patients using an APD cycler machine no longer in use [42] and thus should be carefully interpreted [43]. Another US prospective study of 82 new patients in the late 80 s reported APD superiority with approximately double risk of peritonitis for CAPD vs. APD, but a similar incidence of exit site infections [44]. In a study involving 132 pediatric patients from Turkey the incidence of peritonitis episodes was similar between the two modalities, with an increased incidence of Gram-negative peritonitis in children on APD [45]. In another publication from Canada which included 4247 PD patients between 1996 and 2005, the same risk was reported for peritonitis incidence in both modalities [46]. A study worth mentioning involved 508 peritonitis episodes in 205 patients and showed that APD was associated with a prolonged duration of elevated leukocyte count in the PD dialysate and thus an increased need for long-term antibiotic administration [47]. A prospective study involving ten Nephrology Centers in Scotland with an 8-year follow-up showed lower peritonitis rates for APD compared to CAPD [48]. The results were interpreted with caution, taking into consideration that CAPD patients were older and that the study centers exhibited significant differences. The conflicting results are explained by the different frequency of peritonitis rates among different centers, the small sample often recruited and the short follow-up period after a peritonitis episode. The study by Beduschi et al. that revealed a survival advantage for APD did not show any difference in duration to first peritonitis episode [14]. A longitudinal study from Kuwait showed a lower peritonitis incidence rate for APD compared to CAPD, a higher peritonitis free percentage of patients and a delayed duration to the first peritonitis episode both in favor of APD [19]. In a publication from the ANZDATA registry, no difference in peritonitis rates between the two modalities was shown during a 2-year follow-up of almost 7000 patients in Australia. A longer duration to the first infection episode with Gram-positive microorganisms was noted, a finding more or less expected. On the other hand, the overall infection rate for CAPD was lower in regard to 
Gram-negative microorganisms and higher in regard to culture-negative episodes, findings not fully explained in the study [49].

\section{Intraperitoneal pressure-patient compliance}

The instillation of PD fluid into the peritoneal cavity leads to increased intraperitoneal pressure and may result to hernia formation and PD dialysate leak, causing discomfort in some patients. While APD dialysate instillation is performed in a supine position, in CAPD the dialysate dwell is performed in the upright position and thus intraperitoneal pressure in APD is reduced by more than $50 \%$ compared to CAPD. Hernia incidence has been reported to be lower in APD patients [21], but this has not been confirmed by all studies [13]. In any case, increased PD dialysate volume during the night dwell and lower or even no dialysate volume during daytime (dry day) could be proven beneficial for patients who cannot tolerate high intraperitoneal pressure [50]. In this sense, APD could be a satisfactory alternative to surgical repair of such hernias [6].

Patient compliance to PD prescription is an important issue since a significant proportion of PD patients does not comply with it, leading to devastating consequences for both technique and patient survival [51]. The risk of noncompliance appears to be greater in CAPD rather than APD patients, possibly due to the higher number of connections and disconnections required in CAPD [52], and also due to the discomfort associated with increased intraperitoneal pressure in this modality [53]. One study reported a statistically significant advantage for APD compared to CAPD in regard to patient non-compliance [52].

\section{Residual renal function-blood pressure- ultrafiltration-sodium removal-left ventricular hypertrophy}

Achieving ultrafiltration targets becomes challenging as residual renal function (RRF) declines. It remains controversial if APD really helps in achieving this goal. In a prospective 10-month study of 53 patients on CAPD and 51 on APD, ultrafiltration and sodium removal were lower in patients on APD. Additionally, CAPD patients showed better blood pressure control [54]. However, in the EAPOS over $75 \%$ of 177 anuric APD patients achieved a daily ultrafiltration volume of above $750 \mathrm{~mL}$ [55]. In a Canadian study, 56 APD patients with liberal icodextrin use for the daily dwell were enrolled. Blood pressure control was achieved by $93 \%$ of the patients and volume balance was independent of sodium removal [56]. More recent data showed that blood pressure and volume control were similar between the two modalities, despite the greater sodium removal in CAPD [57]. Similarly, a recent meta-analysis of nine studies comparing dialytic sodium removal between APD and CAPD revealed that CAPD enables higher sodium removal than APD, even though ultrafiltration did not differ. The difference found in sodium removal between the two modalities decreased in high transporters [58]. In a Korean study, where ambulatory blood pressure was monitored for $24 \mathrm{~h}$ in a population of 26 CAPD and 18 APD patients, no significant difference was noted in blood pressure control and in left ventricular hypertrophy (LVH) incidence [59]. On the contrary, in a recent study of 47 CAPD patients short term (3-5 days) application of in-hospital APD was able to increase ultrafiltration, decrease body weight and edema and improve Left Heart Failure (LHF) class [60].The pivotal role of icodextrin in sodium removal has been supported by a number of studies. One study from a Greek Nephrology Center including 46 patients did not show any difference in sodium removal between APD and CAPD patients, and provided proper icodextrin use in both modality groups [61]. A real patient data-based simulation model comparing icodextrin with $2.27 \%$ glucose solutions clearly showed that the use of icodextrin for the long well (day dwell in APD and night dwell in CAPD) resulted in both increased ultrafiltration efficiency and sodium removal across the whole spectrum of peritoneal membrane transport types. The authors also showed equal sodium removal in both modalities [62]. Similarly, a more recent publication reported that sodium removal was not associated with PD modality but increased with the use of icodextrin and with solutions of higher glucose concentration [63]. Based on the above, it seems that given the appropriate adjustment of the prescribed dialysis dose in the case of RRF reduction and the liberal use of icodextrin, APD can be successfully implemented in achieving ultrafiltration goals and euvolemia [64, 65]. Special attention, however, should be given to a randomized cross-over study by Eloot et al., where the increased ultrafiltration achieved with APD was accompanied by a faster decline of RRF but not by an increased solute removal [66]. The possibility of a faster RRF decline in APD patients is a matter of concern especially for patients on NIPD, a by definition intermittent dialytic modality. The findings of these studies may be conflicting, but according to an earlier systematic review, there was no statistically significant reduction in RRF in APD patients [67]. More recent data from the NECOSAD study (Netherlands Cooperative Study on the Adequacy of Dialysis), however, showed that in patients starting on APD, the risk of RRF decline is greater, especially during the first year on APD [68]. This risk was not confirmed in other publications [69, 70] and the two modalities seem equivalent. One more recent study reported that APD patients had a three times higher probability of anuria compared to CAPD. 
Interestingly, this study also showed that major determinants of a faster decline of RRF were the number of exchanges per day and the peritoneal glucose load. This suggested that patients who need an intensive PD regimen are the most prone to a faster deterioration of their renal function independently from the PD modality they use [71].

$\mathrm{LVH}$ is a strong predictor of cardiovascular events in a population free of clinically apparent cardiovascular disease [72]. High LVH incidence has been observed in CAPD patients and it has been associated with significantly high morbidity and mortality in these patients [73]. Two studies by Wang et al. and Bavbek et al. examined the incidence of left ventricular mass index (LVMI) in APD and CAPD patients $[74,75]$. Wang et al. compared LVMI in 22 CAPD and 10 CCPD patients. They found higher LVMI in CCPD patients which was attributed to potential diurnal fluid overload in APD patients [74]. Bavbek et al. included 32 CAPD and 30 APD patients without clinically evident cardiovascular or valvular heart disease. They also revealed a higher LVMI in APD compared to CAPD patients [75]. Yet, Jang et al. found no difference in LVH between 18 APD compared to 26 CAPD patients [59]. Further evaluation is warranted to address the influence of the different PD regimens in LVH.

A modified APD model, named adapted APD (APDA), has been proposed for PD delivery by Fischbach et al. APD-A prescription starts with a short dwell time and a small fill volume for the first two cycles to promote ultrafiltration. For the rest of the exchanges, the fill volume and the dwell time are both increased in an effort to promote uremic toxin removal. In contrast, conventional APD uses same dwell time and fill volume exchanges. In a prospective randomized crossover trial 22 patients were randomized in either conventional or APD-A for a 45-day period and then crossed over to the other APD schedule for another 45 days. APD-A was significantly associated with improved ultrafiltration volumes, sodium and phosphate removal, as well as with a decreased metabolic cost measured by glucose absorption [76].

\section{Phosphate removal}

Removal of excess phosphate is of crucial importance for the health of all end-stage renal disease (ESRD) patients. In the aforementioned study by Moor and coworkers, a higher phosphate removal was dependent only on increased dialysate volume [63]. In a retrospective study of 380 patients, higher phosphate peritoneal removal was associated with the use of CAPD and fast transport status. The authors suggested that low transporters should be advised to use CAPD [77]. The advantageous effect of both fast transport status and CAPD on phosphate removal was confirmed in a recent retrospective study by Davenport on 451 PD patients.
The advantage of CAPD disappeared however, when a day exchange was added to the APD regimen [78]. Summarizing, increased phosphate removal supports CAPD as a more suitable modality for low transporters. For the rest of PD patients CCPD would be recommended when increased phosphate removal is needed.

\section{Quality of life and sleep}

There is a common belief that APD offers better quality of life during the day in exchange of a disturbed sleep. As far as the quality of life of the patients is concerned, relevant bibliographic data do not provide safe conclusions. In a multicenter study from the Netherlands, patients on APD showed better mental health with less anxiety and depression in comparison with patients on CAPD for the same treatment duration. On the other hand, quality of life physical parameters was similar in both groups [79]. In another study from Denmark, APD patients had more time free of dialysis which could be given to work, family and social activities. Less physical and emotional discomfort was also observed in patients on APD, but the difference was not statistically significant [80]. In an interesting yet small study, 18 patients after 6 months on CAPD were transferred for another 6-month period to APD. During the APD period, the patients experienced improvement in parameters such as social functioning and mental health, but again not reaching statistical significance [81]. Similarly, a non-statistically significant trend was shown in a recent Mexican study comparing 39 CAPD, 42 APD and 40 hemodialysis (HD) patients. APD compared to CAPD patients scored non-significantly higher in scales such as Quality of Life, Social Functioning and Physical Functioning [82]. In the same path, a study by Diaz-Buxo et al. with a large number of PD patients (728 on CAPD and 532 on CCPD) failed to show a clear advantage for any of the two modalities. Specifically, CCPD patients compared to CAPD patients scored lower on scales reflecting physical and higher in scales reflecting mental processes. CAPD patients perceived themselves as less physically impaired but not as adjusted as CCPD patients [83]. Subsequent studies also failed to show a difference in quality of life between the two modalities [64, 65, 84]. A meta-analysis of 190 studies examined the quality of life of CKD patients according to the treatment they received. Using a different instrument for quality of life quantification, the study showed statistically significant superiority of APD over CAPD, though this finding was interpreted with caution [85]. In a study of 266 patients in Singapore, published after this meta-analysis, APD patients experienced better physical health and were less bothered by dialysis-related symptoms [86]. 
Sleep disturbance of APD patients was studied in a randomized study by Bro et al. who showed that APD patients experienced more sleeping problems compared to those on CAPD [80]. Additionally, APD has been associated with a higher frequency of daytime drowsiness [64]. In another study, however, sleep quality was similar for both modalities [84], while in a study using polysomnography, APD was associated with an improvement in sleep quality and a lower incidence of sleep apnea, probably due to better volume control during sleep [87] as was later confirmed by the same authors [88]. It is worth mentioning that in a very recent study on APD patients the severity of obstructive sleep apnea was correlated with decreased RRF and not with dialysis-related indices [89]. In the aforementioned recent Mexican study, unrefreshing sleep, a symptom of insomnia, was more common in CAPD, while snoring and witnessed apneas were more frequent in APD patients [82].

In summary, contrary to what may be a common belief, APD and CAPD do not substantially differ in terms of either quality of life or sleep. The only undisputable advantage of APD is that it offers more free daytime.

\section{APD in children and the elderly-assisted PD}

In the United States, 95\% of children and adolescents under the age of 19 suffering from ESRD on PD implement APD [2]. This is also the case in Europe, for example, in Italy [90]. APD exhibits a pivotal role in the management of the pediatric population with ESRD, especially infants. In APD, the fill volume can be accurately determined, which allows improved treatment individualization according to age, body size and metabolic needs of the developing child [91]. APD also offers more free time during the day for children and parents with no exchanges required during school hours [92]. Compared to children on CAPD, children on APD had a lower peritonitis incidence [92]. In a very interesting study, the transfer of more than 300 pediatric patients from CAPD to APD resulted in better ultrafiltration, less edema, lower mean blood pressure, lower peritonitis rates and fewer hospital admissions [93]. Another study from Hong Kong showed impressive results regarding the quality of life of both children undergoing APD and their parents, who experienced a similar quality of life to that of transplanted children and their parents respectively [94].

As far as the elderly are concerned, APD is also the prevailing and preferred dialysis modality for patients on PD. In the United States, over $60 \%$ of patients over the age of 65 on PD undergo APD [2]. Among all patients groups, it is the elderly that mostly need another person to perform the PD dialysate bag exchanges and thus APD seems more viable, as it requires fewer connections [95]. In addition, APD has been proven a reliable modality of renal replacement therapy in patients older than 65 years of age. According to a US study, APD patients of more than 65 years of age showed no difference compared to younger patients in terms of technique failure and peritonitis incidence. Even more importantly quality of life indicators were similar among all age groups of the patients enrolled [96].

A significant number of patients on PD present with the need for a partner, a nurse or another person who could perform the PD dialysate bag exchanges instead of themselves. That is the concept of Assisted PD. In these cases, APD should probably be the modality of choice. In APD only one connection and one disconnection are required on a daily basis. This is an important time-saving advantage that reduces the daily workload of the caregiver and could be proven beneficial even for patients residing in nursing homes $[32,97]$. The latter were confirmed by a Danish study, which enrolled 65 patients undergoing assisted APD and reported satisfactory results (54\% biannual survival and 1 peritonitis episode per 26 patient-months) [98]. A Brazilian observational study included elderly patients with motor and cognitive issues and lack of a supportive environment as well as HD patients with hemodynamic instability or vascular access loss. The study showed that assisted APD is a reliable and effective home HD modality for patients without any other renal replacement therapy alternatives [99].

\section{Effect on peritoneal membrane characteristics and glucose fluctuation}

A study by Michels et al. reported that over a 2-year period, APD patients showed a faster decline in effective lymphatic absorption rate and in transcapillary ultrafiltration. No differential effect was observed in transport status as assessed by the dialysate/plasma creatinine ratio [100]. Another study including 229 patients with a mean follow-up of 5.6 years concluded that APD and CAPD exhibited similar effects in transport characteristics and ultrafiltration efficiency of the peritoneal membrane [101].

In a study of 20 APD and CAPD diabetic patients under a 72-h continuous blood glucose monitoring, PD modality did not significantly influence average blood glucose and glycated hemoglobin levels. However, the fluctuation of blood glucose assessed by the difference in the minimum and maximum glucose values during the monitoring was significantly lower in APD patients [102].

\section{Urgent start of PD}

Both APD and CAPD have been used as the initial dialysis modality in patients requiring urgent dialysis. The association of APD with lower intraperitoneal pressures with the 
patient in the supine position probably makes this modality the best option for urgent PD start. In the case of CAPD for urgent PD start, the high number of small volume exchanges necessary for adequate dialysis without increasing the risk of pericatheter leaking requires a lot of time and effort from the nursing staff. Thus, APD offers a reliable and viable alternative. In a retrospective study from Denmark, patients who started APD in less than $24 \mathrm{~h}$ after PD catheter insertion had a similar technique survival to that of patients who started APD in a planned manner [103]. In two prospective studies from France and India, urgent initiation of APD was proven an efficacious dialysis modality [104, 105]. Moreover, APD has been performed as a frontline urgent dialysis therapy option with good results [106]. Another study compared urgent-start APD with urgent-start CAPD (1-3 days after catheter insertion) and concluded that during the initial 9-day break-in period, APD resulted in better solute clearance, had similar complications but also led to a significant decline in serum albumin. The study suggested that a combination regimen of 6 days on APD followed by 3 days of CAPD was the most appropriate choice [107].

\section{PD during emergencies, pandemics and natural disasters}

The case is similar in a pandemic, such as the novel coronavirus 2019 disease (COVID-19) the world is currently going through. In general, hospitalized patients with acute kidney injury rarely initiate PD and are most often started on HD mainly due to PD catheter-related issues. During the last pandemic, though, the demand for urgent dialysis start was unprecedented. Shortage of HD staff, machines and supplies became apparent and along with dialysis circuit clotting forced many hospitals to turn to PD. In this setting, a recent study included 21 patients needing urgent dialysis initiation and implemented APD with initially low fill volumes, which were gradually increased. The majority of the patients were in the supine position due to a significant compromise of their respiratory system and along with low APD fill volumes the risk of catheter problems was reduced [108]. Unlike CAPD, APD requires the immediate use of cyclers. During health crises, the pressing need of an increased number of APD machines poses as an issue which requires attention. However, in times of pandemics, minimum physical contact between health-care providers and the highly contagious COVID-19 positive patient is warranted. Thus, APD compared to CAPD is probably preferred; since it can be implemented only once daily, the patient can be remotely monitored and the cycler setup can be prepared at a distance from the patient [109].

Natural disasters such as earthquakes, floods and hurricanes as well as electric power blackouts can disrupt dialysis treatment, especially electricity-dependent APD. During the Taiwan Chi-Chi earthquake, 45 APD patients had to switch to CAPD due to electricity failure [110]. CAPD patients, on the other hand, were not affected by electrical power shutdown. In addition, at the time of the Marmara earthquake in Turkey, APD patients connected to the cycler found themselves in an arduous situation of not being able to immediately disconnect $[111,112]$. Yet, CAPD patients did not experience similar issues. Moreover, in the quake aftermath, APD patients described that they suffered from various psychological issues.

\section{Employment and financial issues}

In a study from Finland, similar rates of occupational activity ranging from 39 to $44 \%$ were observed among APD, home HD patients and transplant recipients [113]. In another Hong Kong study, there was a statistically significant difference in the employment status between patients on APD and CAPD [114]. Full-time employment was more common in APD compared to CAPD patients (62.2\% vs. $15 \%$, respectively). Another study from the same research team showed that the most active patients more often choose APD as their initial method of renal replacement therapy. That is the reason why about $50 \%$ of the patients on APD are working, compared to $20 \%$ of HD patients [115].

Among other parameters, patient employment can indirectly affect PD cost. In a study from Taiwan, APD was associated with higher annual dialysis-related cost but lower annual productivity losses compared to CAPD. This resulted in a similar government funded and out-of-pocket total cost [116]. On the contrary, a study in two Italian hospitals concluded that APD had a significantly higher total (direct and indirect) cost when compared to CAPD [117]. In a Greek study, where APD and CAPD direct cost was assessed, APD was found significantly more expensive. Unfortunately, this study did not differentiate the two modalities in terms of indirect cost [118]. In addition, a Spanish study concluded that APD and, to a lesser extent, transplantation, are the modalities associated with the lowest indirect cost due to morbidity in ESRD, resulting in more frequent employment and less disability benefits when compared with HD [119]. In a Mexican study, the direct dialysis procedure-related cost was higher for APD compared to CAPD, but the indirect cost for medication, hospitalization, laboratory tests and surgical procedures between the two modalities was similar [120]. When indirect cost is taken into account, APD seems to have an advantage over CAPD, but when total financial burden to patients, health providers and social security systems are taken into account, the modalities account for similar cost. 


\section{When should APD be applied?}

For patients who fail to achieve clearance and ultrafiltration goals with CAPD, APD is a viable alternative. In these cases, the increased number of changes in CAPD, at the expense of quality of life, may lead patients to transfer to hemodialysis. Thus, APD implementation with higher dialysate volumes, longer nighttime sessions, especially in combination with icodextrin use for the long day dwell, or the addition of a daily manual change (enhanced CCPD-CCPD plus) could prolong technique survival. In low transporters, a program with less frequent changes overnight and possible addition of a manual exchange during the day could be used instead. Another medical indication for APD is the absolute need to avoid a high intraperitoneal pressure since it is implemented in the supine, while CAPD is performed in the upright position. Last, but not least, patient's preference is of utmost importance. Family and social background, working status and patient's lifestyle are important aspects when initiating PD. Thus, APD is more suitable for children, elderly and patients who need assistance in performing the method. However, no conclusive data suggest any solid advantage of CAPD over APD in terms of RRF preservation and APD cannot be contraindicated on the basis of preserving RRF.

\section{Conclusions}

Automated PD is the most promising PD technique with unquestionable advantages in patient's lifestyle. Yet, it is more than true that the potential clinical benefits of APD implementation are under discussion with only the high peritoneal membrane permeability being a strong indication for its use so far. APD offers a variety of options, facilitates patients who have a job and saves more time for personal and family activities. APD is suitable for children, elderly and patients who need assistance in treatment implementation. It has been previously suggested that APD should be always used in accordance to patient preference, an aspect never to be overlooked at PD initiation [121]. However, a real-life assessment in a Brazilian study revealed a different picture with significant disparities in the utilization of APD. APD patients were more likely white, better educated, with a lower BMI and less comorbidities. The authors of this manuscript totally agree with the conclusion of the Brazilian study that limiting APD implementation may be unethical and that demographic and socioeconomic status should not be a part of the decision-making process in PD modality choice [122]. Acceptance and application of patient's preference regarding the method of renal replacement therapy has a positive effect on quality of life [123], which is probably the most important parameter in the treatment of ESRD. In our opinion, APD should be made readily available to all patients starting PD.

\section{References}

1. Kramer A, Pippias M, Noordzij M, Stel VS, Afentakis N, Ambuhl PM, Andrusev AM, Fuster EA, Monzon AFE, Asberg A, Barbullushi M, Bonthuis M, Caskey FJ, de la Nuez CP, Cernevskis H, des Grottes JM, Garneata L, Golan E, Hemmelder MH, Ioannou K, Jarraya F, Kolesnyk M, Komissarov K, Lassalle M, Macario F, Mahillo-Duran B, Martin de Francisco AL, Palsson R, Pechter U, Resic H, Rutkowski B, Santiuste de Pablos C, Seyahi N, Simic Ogrizovic S, Slon Roblero MF, Spustova V, Stojceva-Taneva O, Traynor J, Massy ZA, Jager KJ, (2018) The European Renal Association-European Dialysis and Transplant Association (ERA-EDTA) Registry Annual Report 2015: a summary. Clin Kidney J 11(1):108-122. https://doi.org/10.1093/ckj/sfx149

2. US Renal Data System 2016 Annual Data Report: Epidemiology of Kidney Disease in the United States (2017) Am J Kidney 69 (3S1):A4. https://doi.org/10.1053/j.ajkd.2017.01.036

3. Canadian Institute for Health Information (2018) Treatment of End-Stage Organ Failure in Canada, Canadian Organ Replacement Register, 2009 to 2018: End-Stage Kidney Disease and Kidney Transplants - Data Tables. Ottawa, ON: CIHI; 2019

4. ANZDATA Registry 41st report (2018) Chapter 5: peritoneal dialysis. Australia and New Zealand Dialysis and Transplant Registry. Adelaide, Australia. 2018. https://www.anzdata.org. au. Accessed July 2020

5. Jain AK, Blake P, Cordy P, Garg AX (2012) Global trends in rates of peritoneal dialysis. J Am Soc Nephrol JASN 23(3):533544. https://doi.org/10.1681/ASN.2011060607

6. Tang SC, Lai KN (2007) Does automated peritoneal dialysis provide better outcomes than continuous ambulatory peritoneal dialysis? Nat Clin Pract Nephrol 3(11):596-597. https://doi. org/10.1038/ncpneph0616

7. Piraino B (2017) Innovations in treatment delivery, risk of peritonitis, and patient retention on peritoneal dialysis. Semin Dial 30(2):158-163. https://doi.org/10.1111/sdi.12571

8. Blake PG (2006) Cycling forward. Perit Dial Int 26(3):306-308

9. Guo A, Mujais S (2003) Patient and technique survival on peritoneal dialysis in the United States: evaluation in large incident cohorts. Kidney Int Suppl 88:S3-12

10. Mujais S, Story K (2006) Peritoneal dialysis in the US: evaluation of outcomes in contemporary cohorts. Kidney Int Suppl 103:S21-26. https://doi.org/10.1038/sj.ki.5001912

11. Sun CY, Lee CC, Lin YY, Wu MS (2011) In younger dialysis patients, automated peritoneal dialysis is associated with better long-term patient and technique survival than is continuous ambulatory peritoneal. Perit Dial Int 31(3):301-307. https://doi. org/10.3747/pdi.2010.00072

12. Katavetin P, Theerasin Y, Treamtrakanpon W, Saiprasertkit N, Kanjanabuch T (2013) Treatment failure in automated peritoneal dialysis and double-bag continuous ambulatory peritoneal dialysis. Nephrology 18(8):545-548. https://doi.org/10.1111/ nep. 12107

13. Rabindranath KS, Adams J, Ali TZ, Daly C, Vale L, Macleod AM (2007) Automated vs continuous ambulatory peritoneal dialysis: a systematic review of randomized controlled trials. Nephrol Dial Transplant 22(10):2991-2998. https://doi.org/10.1093/ ndt/gfm515 
14. Beduschi Gde C, Figueiredo AE, Olandoski M, Pecoits-Filho R, Barretti P, de Moraes TP, all centers that contributed to the B (2015) Automated peritoneal dialysis is associated with better survival rates compared to continuous ambulatory peritoneal dialysis: a propensity score matching analysis. PLoS ONE 10(7):e0134047. https://doi.org/10.1371/journal.pone.0134047

15. Tang CH, Chen TH, Fang TC, Huang SY, Huang KC, Wu YT, Wang CC, Sue YM (2016) Do automated peritoneal dialysis and continuous ambulatory peritoneal dialysis have the same clinical outcomes? A ten-year cohort study in Taiwan. Sci Rep 6:29276. https://doi.org/10.1038/srep29276

16. See EJ, Johnson DW, Hawley CM, Pascoe EM, Badve SV, Boudville N, Clayton PA, Sud K, Polkinghorne KR, Borlace M, Cho Y (2018) Risk predictors and causes of technique failure within the first year of peritoneal dialysis: an australia and New Zealand dialysis and transplant registry (ANZDATA) Study. Am J Kidney Dis 72(2):188-197. https://doi.org/10.1053/j.ajkd.2017.10.019

17. Liakopoulos V, Stefanidis I, Mertens PR (2018) The importance of icodextrin use for technique and patient survival in peritoneal dialysis. Am J Kidney Dis 72(2):309. https://doi.org/10.1053/j. ajkd.2018.01.053

18. Wang IK, Lu CY, Muo CH, Chang CT, Yen TH, Huang CC, Li TC, Sung FC (2016) Analysis of technique and patient survival over time in patients undergoing peritoneal dialysis. Int Urol Nephrol 48(7):1177-1185. https://doi.org/10.1007/s1125 5-016-1296-x

19. El-Reshaid W, Al-Disawy H, Nassef H, Alhelaly U (2016) Comparison of peritonitis rates and patient survival in automated and continuous ambulatory peritoneal dialysis: a 10-year single center experience. Ren Fail 38(8):1187-1192. https://doi. org/10.1080/0886022X.2016.1209025

20. Li X, Xu H, Chen N, Ni Z, Chen M, Chen L, Dong J, Fang W, Yu Y, Yang X, Chen J, Yu X, Yao Q, Sloand JA, Marshall MR (2018) The effect of automated versus continuous ambulatory peritoneal dialysis on mortality risk in China. Perit Dial Int 38(Suppl 2):S25-S35. https://doi.org/10.3747/pdi.2017.00235

21. Dombros N, Dratwa M, Feriani M, Gokal R, Heimburger O, Krediet R, Plum J, Rodrigues A, Selgas R, Struijk D, Verger C, Dialysis EEGoP (2005) European best practice guidelines for peritoneal dialysis. 6 Automated peritoneal dialysis. Nephrol Dial Transplant 20(Suppl 9):ix21-ix23. https://doi.org/10.1093/ ndt/gfil120

22. Mujais S, Nolph K, Gokal R, Blake P, Burkart J, Coles G, Kawaguchi Y, Kawanishi H, Korbet S, Krediet R, Lindholm B, Oreopoulos D, Rippe B, Selgas R (2000) Evaluation and management of ultrafiltration problems in peritoneal dialysis. International Society for Peritoneal Dialysis Ad Hoc Committee on Ultrafiltration Management in Peritoneal Dialysis. Perit Dial Int 20(Suppl 4):S5-21

23. Churchill DN, Thorpe KE, Nolph KD, Keshaviah PR, Oreopoulos DG, Page D (1998) Increased peritoneal membrane transport is associated with decreased patient and technique survival for continuous peritoneal dialysis patients. The Canada-USA (CANUSA) Peritoneal Dialysis Study Group. J Am Soc Nephrol JASN 9(7):1285-1292

24. Davies SJ, Phillips L, Russell GI (1998) Peritoneal solute transport predicts survival on CAPD independently of residual renal function. Nephrol Dial Transplant 13(4):962-968. https://doi. org/10.1093/ndt/13.4.962

25. Rumpsfeld M, McDonald SP, Johnson DW (2006) Higher peritoneal transport status is associated with higher mortality and technique failure in the Australian and New Zealand peritoneal dialysis patient populations. J Am Soc Nephrol JASN 17(1):271278. https://doi.org/10.1681/ASN.2005050566

26. Brown EA, Davies SJ, Rutherford P, Meeus F, Borras M, Riegel W, Divino Filho JC, Vonesh E, van Bree M (2003)
Survival of functionally anuric patients on automated peritoneal dialysis: the European APD Outcome Study. J Am Soc Nephrol JASN 14(11):2948-2957. https://doi.org/10.1097/01. asn.0000092146.67909.e2

27. Yang X, Fang W, Bargman JM, Oreopoulos DG (2008) High peritoneal permeability is not associated with higher mortality or technique failure in patients on automated peritoneal dialysis. Perit Dialysis Int 28(1):82-92

28. Johnson DW, Hawley CM, McDonald SP, Brown FG, Rosman JB, Wiggins KJ, Bannister KM, Badve SV (2010) Superior survival of high transporters treated with automated versus continuous ambulatory peritoneal dialysis. Nephrol Dial Transplant 25(6):1973-1979. https://doi.org/10.1093/ndt/gfp780

29. Chung SH, Heimburger O, Lindholm B (2008) Poor outcomes for fast transporters on PD: the rise and fall of a clinical concern. Semin Dial 21(1):7-10. https://doi.org/10.1111/j.1525139X.2007.00327.x

30. Liakopoulos V, Nikitidou O, Kalathas T, Roumeliotis S, Salmas M, Eleftheriadis T (2017) Peritoneal dialysis-related infections recommendations: 2016 update. What is new? Int Urol Nephrol 49(12):2177-2184. https://doi.org/10.1007/s1125 5-017-1632-9

31. Li PK, Szeto CC, Piraino B, de Arteaga J, Fan S, Figueiredo AE, Fish DN, Goffin E, Kim YL, Salzer W, Struijk DG, Teitelbaum I, Johnson DW (2016) ISPD peritonitis recommendations: 2016 update on prevention and treatment. Perit Dial Int 36(5):481508. https://doi.org/10.3747/pdi.2016.00078

32. Wilson J, Nissenson AR (2002) Determinants in APD selection. Semin Dial 15(6):388-392. https://doi.org/10.1046/j.1525139x.2002.00097.x

33. Tomo T, Okabe E, Matsuyama K, Iwashita T, Yufu K, Nasu M (2005) The effect of peritoneal rest in combination therapy of peritoneal dialysis and hemodialysis: using the cultured human peritoneal mesothelial cell model. J Artif Organs 8(2):125-129. https://doi.org/10.1007/s10047-005-0290-3

34. Huang JW, Hung KY, Yen CJ, Wu KD, Tsai TJ (2001) Comparison of infectious complications in peritoneal dialysis patients using either a twin-bag system or automated peritoneal dialysis. Nephrol Dial Transplant 16(3):604-607. https://doi.org/10.1093/ ndt/16.3.604

35. Davenport A (2009) Peritonitis remains the major clinical complication of peritoneal dialysis: the London, UK, peritonitis audit 2002-2003. Perit Dialysis Int 29(3):297-302

36. Basile C, De Padova F (2001) Comparison of peritonitis incidence in CAPD and automated peritoneal dialysis. Nephrol Dial Transplant 16(9):1957-1958. https://doi.org/10.1093/ ndt/16.9.1957

37. Ghahramani N, Gorban-Brennan N, Kliger AS, Finkelstein FO (1995) Infection rates in end-stage renal disease patients treated with CCPD and CAPD using the UltraBag system. Adv Perit Dial Conf Perit Dial 11:164-167

38. Troidle LK, Gorban-Brennan N, Kliger AS, Finkelstein FO (1998) Continuous cycler therapy, manual peritoneal dialysis therapy, and peritonitis. Adv Perit Dial Conf Perit Dial $14: 137-141$

39. Rodriguez-Carmona A, Perez Fontan M, Garcia Falcon T, Fernandez Rivera C, Valdes F (1999) A comparative analysis on the incidence of peritonitis and exit-site infection in CAPD and automated peritoneal dialysis. Perit Dialysis Int 19(3):253-258

40. Locatelli AJ, Marcos GM, Gomez MG, Alvarez SA, DeBenedetti LC (1999) Comparing peritonitis in continuous ambulatory peritoneal dialysis patients versus automated peritoneal dialysis patients. Adv Perit Dial Conf Perit Dial 15:193-196

41. Sanchez AR, Madonia C, Rascon-Pacheco RA (2008) Improved patient/technique survival and peritonitis rates in patients treated with automated peritoneal dialysis when compared to continuous 
ambulatory peritoneal dialysis in a Mexican PD center. Kidney Int Suppl 108:S76-80. https://doi.org/10.1038/sj.ki.5002606

42. de Fijter CW, Oe LP, Nauta JJ, van der Meulen J, Verbrugh HA, Verhoef J, Donker AJ (1994) Clinical efficacy and morbidity associated with continuous cyclic compared with continuous ambulatory peritoneal dialysis. Ann Intern Med 120(4):264-271. https://doi.org/10.7326/0003-4819-120-4-199402150-00002

43. Nessim SJ, Bargman JM (2008) Occurrence of peritonitis in APD versus CAPD: methodologic problems. Nephrol Dial Transplant 23(5):1769-1770. https://doi.org/10.1093/ndt/gfm902(author reply 1770)

44. Holley JL, Bernardini J, Piraino B (1990) Continuous cycling peritoneal dialysis is associated with lower rates of catheter infections than continuous ambulatory peritoneal dialysis. Am J Kidney Dis 16(2):133-136. https://doi.org/10.1016/s0272 -6386(12)80567-1

45. Akman S, Bakkaloglu SA, Ekim M, Sever L, Noyan A, Aksu N (2009) Peritonitis rates and common microorganisms in continuous ambulatory peritoneal dialysis and automated peritoneal dialysis. Pediatr Int 51(2):246-249. https://doi.org/10.1111/j.1442200X.2008.02693.X

46. Nessim SJ, Bargman JM, Austin PC, Nisenbaum R, Jassal SV (2009) Predictors of peritonitis in patients on peritoneal dialysis: results of a large, prospective Canadian database. Clin J Am Soc Nephrol CJASN 4(7):1195-1200. https://doi.org/10.2215/ CJN.00910209

47. Ruger W, van Ittersum FJ, Comazzetto LF, Hoeks SE, ter Wee PM (2011) Similar peritonitis outcome in CAPD and APD patients with dialysis modality continuation during peritonitis. Perit Dial Int 31(1):39-47. https://doi.org/10.3747/ pdi.2009.00235

48. Brown MC, Simpson K, Kerssens JJ, Mactier RA, Scottish Renal R (2011) Peritoneal dialysis-associated peritonitis rates and outcomes in a national cohort are not improving in the postmillennium (2000-2007). Perit Dial Int 31(6):639-650. https:// doi.org/10.3747/pdi.2010.00185

49. Lan PG, Johnson DW, McDonald SP, Boudville N, Borlace M, Badve SV, Sud K, Clayton PA (2014) The association between peritoneal dialysis modality and peritonitis. Clin J Am Soc Nephrol CJASN 9(6):1091-1097. https://doi.org/10.2215/CJN.09730 913

50. Clinical practice recommendations for peritoneal dialysis adequacy (2006) Am J Kidney Dis 48(Suppl 1):S130-158. doi:https ://doi.org/10.1053/j.ajkd.2006.04.013

51. Raj DS (2002) Role of APD in compliance with therapy. Semin Dial 15(6):434-436. https://doi.org/10.1046/j.1525139x.2002.00107.x

52. Bernardini J, Nagy M, Piraino B (2000) Pattern of noncompliance with dialysis exchanges in peritoneal dialysis patients. Am J Kidney Dis 35(6):1104-1110. https://doi.org/10.1016/s0272 -6386(00)70047-3

53. Caruana RJ, Smith KL, Hess CP, Perez JC, Cheek PL (1989) Dialysate dumping: a novel cause of inadequate dialysis in continuous ambulatory peritoneal dialysis (CAPD) patients. Perit Dial Int 9(4):319-320

54. Rodriguez-Carmona A, Perez-Fontan M, Garca-Naveiro R, Villaverde P, Peteiro J (2004) Compared time profiles of ultrafiltration, sodium removal, and renal function in incident CAPD and automated peritoneal dialysis patients. Am J Kidney Dis 44(1):132-145. https://doi.org/10.1053/j.ajkd.2004.03.035

55. Brown EA, Davies SJ, Heimburger O, Meeus F, Mellotte G, Rosman J, Rutherford P, Van Bree M, European Automated Peritoneal Dialysis Outcomes Study I (2001) Adequacy targets can be met in anuric patients by automated peritoneal dialysis: baseline data from EAPOS. Perit Dial Int 21(Suppl 3):S133-137
56. Boudville NC, Cordy P, Millman K, Fairbairn L, Sharma A, Lindsay R, Blake PG (2007) Blood pressure, volume, and sodium control in an automated peritoneal dialysis population. Perit Dial Int 27(5):537-543

57. Cnossen TT, Konings CJ, Fagel WJ, van der Sande FM, van Geel K, Leunissen KM, Kooman JP (2012) Fluid state and blood pressure control: no differences between APD and CAPD. ASAIO J 58(2):132-136. https://doi.org/10.1097/MAT.0b013e318245224 7

58. Borrelli S, La Milia V, De Nicola L, Cabiddu G, Russo R, Provenzano M, Minutolo R, Conte G, Garofalo C, Study group Peritoneal Dialysis of Italian Society of N (2019) Sodium removal by peritoneal dialysis: a systematic review and metaanalysis. J Nephrol 32(2):231-239. https://doi.org/10.1007/s4062 0-018-0507-1

59. Jang JS, Kwon SK, Kim HY (2011) Comparison of Blood Pressure Control and Left Ventricular Hypertrophy in Patients on Continuous Ambulatory Peritoneal Dialysis (CAPD) and Automated Peritoneal Dialysis (APD). Electrolyte Blood Press E \& BP 9(1):16-22. https://doi.org/10.5049/EBP.2011.9.1.16

60. Yang C, Liu J, Gong N, Lin Y, He Y, Yi Z, Hu L, Jiang J, Ai J (2018) Automated peritoneal dialysis could rapidly improve left heart failure by increasing peritoneal dialysis ultrafiltration: a single-center observational clinical study. Clin Nephrol 89(6):422-430. https://doi.org/10.5414/CN109303

61. Fourtounas C, Dousdampanis P, Hardalias A, Vlachojannis JG (2013) Sodium removal and peritoneal dialysis modalities: no differences with optimal prescription of icodextrin. Artif Organs 37(7):E107-113. https://doi.org/10.1111/aor.12061

62. Akonur A, Firanek CA, Gellens ME, Hutchcraft AM, Kathuria P, Sloand JA (2016) Volume-based peritoneal dialysis prescription guide to achieve adequacy targets. Perit Dial Int 36(2):188-195. https://doi.org/10.3747/pdi.2014.00255

63. Moor V, Wagner R, Sayer M, Petsch M, Rueb S, Haring HU, Heyne N, Artunc F (2017) Routine monitoring of sodium and phosphorus removal in peritoneal dialysis (PD) patients treated with continuous ambulatory PD (CAPD), automated PD (APD) or combined CAPD+APD. Kidney Blood Press Res 42(2):257266. https://doi.org/10.1159/000477422

64. Bilgic A, Akman B, Sezer S, Arat Z, Ozelsancak R, Ozdemir N (2011) Daytime sleepiness and quality of life in peritoneal dialysis patients. Ther Apher Dial 15(6):565-571. https://doi. org/10.1111/j.1744-9987.2011.00987.x

65. Michels WM, van Dijk S, Verduijn M, le Cessie S, Boeschoten EW, Dekker FW, Krediet RT, Group NS (2011) Quality of life in automated and continuous ambulatory peritoneal dialysis. Perit Dial Int 31(2):138-147. https://doi.org/10.3747/pdi.2010.00063

66. Eloot S, Vanholder R, Dequidt C, Van Biesen W (2015) Removal of different classes of uremic toxins in APD vs CAPD: a randomized cross-over study. Perit Dial Int 35(4):436-442. https:// doi.org/10.3747/pdi.2013.00202

67. Marron B, Remon C, Perez-Fontan M, Quiros P, Ortiz A (2008) Benefits of preserving residual renal function in peritoneal dialysis. Kidney Int Suppl 108:S42-51. https://doi.org/10.1038/ sj.ki.5002600

68. Michels WM, Verduijn M, Grootendorst DC, le Cessie S, Boeschoten EW, Dekker FW, Krediet RT, Group Ns (2011) Decline in residual renal function in automated compared with continuous ambulatory peritoneal dialysis. Clin J Am Soc Nephrol CJASN 6(3):537-542. https://doi.org/10.2215/CJN.00470110

69. Cnossen TT, Usvyat L, Kotanko P, van der Sande FM, Kooman JP, Carter M, Leunissen KM, Levin NW (2011) Comparison of outcomes on continuous ambulatory peritoneal dialysis versus automated peritoneal dialysis: results from a USA database. Perit Dial Int 31(6):679-684. https://doi.org/10.3747/pdi.2010.00004 
70. Balasubramanian G, McKitty K, Fan SL (2011) Comparing automated peritoneal dialysis with continuous ambulatory peritoneal dialysis: survival and quality of life differences? Nephrol Dial Transplant 26(5):1702-1708. https://doi.org/10.1093/ndt/gfq607

71. Perez Fontan M, Remon Rodriguez C, Borras Sans M, Sanchez Alvarez E, da Cunha NM, Quiros Ganga P, Lopez-Calvino B, Rodriguez Suarez C, Rodriguez-Carmona A (2014) Compared decline of residual kidney function in patients treated with automated peritoneal dialysis and continuous ambulatory peritoneal dialysis: a multicenter study. Nephron Clin Pract 128(3-4):352360. https://doi.org/10.1159/000368933

72. Levy D, Garrison RJ, Savage DD, Kannel WB, Castelli WP (1990) Prognostic implications of echocardiographically determined left ventricular mass in the Framingham Heart Study. N Engl J Med 322(22):1561-1566. https://doi.org/10.1056/NEJM1 99005313222203

73. Silaruks S, Sirivongs D, Chunlertrith D (2000) Left ventricular hypertrophy and clinical outcome in CAPD patients. Perit Dial Int 20(4):461-466

74. Wang MC, Tseng CC, Tsai WC, Huang JJ (2001) Blood pressure and left ventricular hypertrophy in patients on different peritoneal dialysis regimens. Perit Dial Int 21(1):36-42

75. Bavbek N, Akay H, Altay M, Uz E, Turgut F, Uyar ME, Karanfil A, Selcoki Y, Akcay A, Duranay M (2007) Serum BNP concentration and left ventricular mass in CAPD and automated peritoneal dialysis patients. Perit Dial Int 27(6):663-668

76. Fischbach M, Issad B, Dubois V, Taamma R (2011) The beneficial influence on the effectiveness of automated peritoneal dialysis of varying the dwell time (short/long) and fill volume (small/ large): a randomized controlled trial. Perit Dial Int 31(4):450 458. https://doi.org/10.3747/pdi.2010.00146

77. Courivaud C, Davenport A (2016) phosphate removal by peritoneal dialysis: the effect of transporter status and peritoneal dialysis prescription. Perit Dial Int 36(1):85-93. https://doi. org/10.3747/pdi.2014.00173

78. Davenport A (2017) Peritoneal phosphate clearance: the effect of peritoneal dialysis modality and peritoneal transport status. Adv Perit Dial Conf Perit Dial 33(2017):6-12

79. de Wit GA, Merkus MP, Krediet RT, de Charro FT (2001) A comparison of quality of life of patients on automated and continuous ambulatory peritoneal dialysis. Perit Dial Int 21(3):306-312

80. Bro S, Bjorner JB, Tofte-Jensen P, Klem S, Almtoft B, Danielsen H, Meincke M, Friedberg M, Feldt-Rasmussen B (1999) A prospective, randomized multicenter study comparing APD and CAPD treatment. Perit Dial Int 19(6):526-533

81. Sunder S, Kalra OP, Nashine S, Waghmare V, Ruchi R (2008) Comparative study of adequacy of dialysis and health-related quality of life in patients on CAPD and APD. Perit Dial Int 28(5):542-544

82. Reynaga-Ornelas L, Baldwin CM, Arcoleo K, Quan SF (2019) Impact of sleep and dialysis mode on quality of life in a Mexican population. Southwest J Pulm Crit care 18(5):122-134. https:// doi.org/10.13175/swjpcc017-19

83. Diaz-Buxo JA, Lowrie EG, Lew NL, Zhang H, Lazarus JM (2000) Quality-of-life evaluation using Short Form 36: comparison in hemodialysis and peritoneal dialysis patients. Am J Kidney Dis 35(2):293-300. https://doi.org/10.1016/s0272 -6386(00)70339-8

84. Guney I, Solak Y, Atalay H, Yazici R, Altintepe L, Kara F, Yeksan M, Turk S (2010) Comparison of effects of automated peritoneal dialysis and continuous ambulatory peritoneal dialysis on health-related quality of life, sleep quality, and depression. Hemodial Int Int Symp Home Hemodial 14(4):515-522. https:// doi.org/10.1111/j.1542-4758.2010.00465.x

85. Wyld M, Morton RL, Hayen A, Howard K, Webster AC (2012) A systematic review and meta-analysis of utility-based quality of life in chronic kidney disease treatments. PLoS Med 9(9):e1001307. https://doi.org/10.1371/journal.pmed.1001307

86. Yang F, Luo N, Lau T, Yu ZL, Foo MWY, Griva K (2018) Health-related quality of life in patients treated with continuous ambulatory peritoneal dialysis and automated peritoneal dialysis in Singapore. PharmacoEconomics Open 2(2):203208. https://doi.org/10.1007/s41669-017-0046-z

87. Tang SC, Lam B, Ku PP, Leung WS, Chu CM, Ho YW, Ip MS, Lai KN (2006) Alleviation of sleep apnea in patients with chronic renal failure by nocturnal cycler-assisted peritoneal dialysis compared with conventional continuous ambulatory peritoneal dialysis. J Am Soc Nephrol JASN 17(9):2607-2616. https://doi.org/10.1681/ASN.2005090936

88. Tang SC, Lam B, Lai AS, Pang CB, Tso WK, Khong PL, Ip MS, Lai KN (2009) Improvement in sleep apnea during nocturnal peritoneal dialysis is associated with reduced airway congestion and better uremic clearance. Clin J Am Soc Nephrol CJASN 4(2):410-418. https://doi.org/10.2215/CJN.03520708

89. Lanis A, Kerns E, Hu SL, Bublitz MH, Risica P, Martin S, Parker J, Millman R, Dworkin LD, Bourjeily G (2018) Residual renal function and obstructive sleep apnea in peritoneal dialysis: a pilot study. Lung 196(4):425-431. https://doi. org/10.1007/s00408-018-0127-5

90. Verrina E, Edefonti A, Gianoglio B, Rinaldi S, Sorino P, Zacchello G, Lavoratti G, Maringhini S, Pecoraro C, Calevo MG, Turrini Dertenois L, Perfumo F (2004) A multicenter experience on patient and technique survival in children on chronic dialysis. Pediatric Nephrol 19(1):82-90. https://doi. org/10.1007/s00467-003-1270-6

91. Verrina E, Cappelli V, Perfumo F (2009) Selection of modalities, prescription, and technical issues in children on peritoneal dialysis. Pediatric Nephrol 24(8):1453-1464. https://doi. org/10.1007/s00467-008-0848-4

92. Fine RN, Ho M, Cooperative NAPRT, S, (2002) The role of APD in the management of pediatric patients: a report of the North American Pediatric Renal Transplant Cooperative Study. Semin Dial 15(6):427-429. https://doi.org/10.1046/j.1525139x.2002.00105.x

93. Fabian Velasco R, Lagunas Munoz J, Sanchez Saavedra V, Mena Brito Trejo JE, Qureshi AR, Garcia-Lopez E, Divino Filho JC (2008) Automated peritoneal dialysis as the modality of choice: a single-center, 3 -year experience with 458 children in Mexico. Pediatric Nephrol 23(3):465-471. https://doi. org/10.1007/s00467-007-0638-4

94. Chiu MC, Ng CF, Lee LP, Lai WM, Lau SC (2007) Automated peritoneal dialysis in children and adolescents-benefits: a survey of patients and parents on health-related quality of life. Perit Dial Int 27(Suppl 2):S138-142

95. Oreopoulos D, Thodis E, Paraskevas KI (2008) The promising future of long-term peritoneal dialysis. Int Urol Nephrol 40(2):405-410. https://doi.org/10.1007/s11255-008-9370-7

96. Kadambi P, Troidle L, Gorban-Brennan N, Kliger AS, Finkelstein FO (2002) APD in the elderly. Semin Dial 15(6):430433. https://doi.org/10.1046/j.1525-139x.2002.00106.x

97. Blake PG (1999) Advantages and disadvantages of automated peritoneal dialysis compared to continuous ambulatory peritoneal dialysis. Perit Dial Int 19(Suppl 2):S121-124

98. Povlsen JV, Ivarsen P (2005) Assisted automated peritoneal dialysis (AAPD) for the functionally dependent and elderly patient. Perit Dial Int 25(Suppl 3):S60-63

99. Franco MR, Fernandes N, Ribeiro CA, Qureshi AR, DivinoFilho JC, da Gloria LM (2013) A Brazilian experience in assisted automated peritoneal dialysis: a reliable and effective home care approach. Perit Dial Int 33(3):252-258. https://doi. org/10.3747/pdi.2012.00031 
100. Michels WM, Verduijn M, Parikova A, Boeschoten EW, Struijk DG, Dekker FW, Krediet RT (2012) Time course of peritoneal function in automated and continuous peritoneal dialysis. Perit Dial Int 32(6):605-611. https://doi.org/10.3747/pdi.2011.00166

101. Samad N, Fan SL (2017) Comparison of change in peritoneal function in patients on continuous ambulatory PD vs automated PD. Perit Dial Int 37(6):627-632. https://doi.org/10.3747/ pdi.2016.00101

102. Okada E, Oishi D, Sakurada T, Yasuda T, Shibagaki Y (2015) A Comparison study of glucose fluctuation during automated peritoneal dialysis and continuous ambulatory peritoneal dialysis. Adv Perit Dial Conf Perit Dial 31:34-37

103. Povlsen JV, Ivarsen P (2006) How to start the late referred ESRD patient urgently on chronic APD. Nephrol Dial Transplant 21(Suppl 2):ii56-59. https://doi.org/10.1093/ndt/gfl192

104. Lobbedez T, Lecouf A, Ficheux M, Henri P, Hurault de Ligny B, Ryckelynck JP (2008) Is rapid initiation of peritoneal dialysis feasible in unplanned dialysis patients? A single-centre experience. Nephrol Dial Transplant 23(10):3290-3294. https://doi. org/10.1093/ndt/gfn213

105. Nayak KS, Subhramanyam SV, Pavankumar N, Antony S, Sarfaraz Khan MA (2018) Emergent start peritoneal dialysis for end-stage renal disease: outcomes and advantages. Blood Purif 45(4):313-319. https://doi.org/10.1159/000486543

106. Ilabaca-Avendano MB, Yarza-Solorzano G, Rodriguez-Valenzuela J, Arcinas-Fausto G, Ramirez-Hernandez V, HernandezHernandez DA, Jauregui-Flores LA (2008) Automated peritoneal dialysis as a lifesaving therapy in an emergency room: report of four cases. Kidney Int Suppl 108:S173-176. https://doi. org/10.1038/sj.ki.5002620

107. Liu S, Zhuang X, Zhang M, Wu Y, Liu M, Guan S, Liu S, Miao L, Cui W (2018) Application of automated peritoneal dialysis in urgent-start peritoneal dialysis patients during the break-in period. Int Urol Nephrol 50(3):541-549. https://doi.org/10.1007/ s11255-018-1785-

108. El Shamy O, Patel N, Abdelbaset MH, Chenet L, Tokita J, Lookstein R, Lee DS, Cohen NA, Sharma S, Uribarri J (2020) Acute start peritoneal dialysis during the COVID-19 pandemic: outcomes and experiences. J Am Soc Nephrol JASN 31(8):16801682. https://doi.org/10.1681/ASN.2020050599

109. Parapiboon W, Ponce D, Cullis B (2020) Acute peritoneal dialysis in COVID-19. Perit Dial Int 40(4):359-362. https://doi. org/10.1177/0896860820931235

110. Hwang SJ, Shu KH, Lain JD, Yang WC (2001) Renal replacement therapy at the time of the Taiwan Chi-Chi earthquake. Nephrol Dial Transplant 16(Suppl 5):78-82. https://doi. org/10.1093/ndt/16.suppl_5.78

111. Ozener C, Ozdemir D, Bihorac A (2000) The impact of the earthquake in northwestern Turkey on the continuous ambulatory peritoneal dialysis patients who were living in the earthquake zone. Adv Perit Dial Conf Perit Dial 16:182-185

112. Sever MS, Lameire N, Van Biesen W, Vanholder R (2015) Disaster nephrology: a new concept for an old problem. Clini Kidney J 8(3):300-309. https://doi.org/10.1093/ckj/sfv024

113. Helantera I, Haapio M, Koskinen P, Gronhagen-Riska C, Finne $\mathrm{P}$ (2012) Employment of patients receiving maintenance dialysis and after kidney transplant: a cross-sectional study from Finland. Am J Kidney Dis 59(5):700-706. https://doi.org/10.1053/j. ajkd.2011.08.025

114. Kwan BC, Chow KM, Ma TK, Yu V, Law MC, Leung CB, Li PK, Szeto CC (2013) Automated peritoneal dialysis in Hong Kong: there are two distinct groups of patients. Nephrology 18(5):356-364. https://doi.org/10.1111/nep.12049

115. Julian Mauro JC, Molinuevo Tobalina JA, Sanchez Gonzalez JC (2012) Employment in the patient with chronic kidney disease related to renal replacement therapy. Nefrologia 32(4):439-445. https://doi.org/10.3265/Nefrologia.pre2012.Apr.11366

116. Tang CH, Wu YT, Huang SY, Chen HH, Wu MJ, Hsu BG, Tsai JC, Chen TH, Sue YM (2017) Economic costs of automated and continuous ambulatory peritoneal dialysis in Taiwan: a combined survey and retrospective cohort analysis. BMJ Open 7(3):e015067. https://doi.org/10.1136/bmjopen-2016-015067

117. Vaccaro CM, Sopranzi F (2017) A comparison between the costs of dialysis treatments in Marche Region, Italy: Macerata and Tolentino hospitals. Annali dell'Istituto superiore di sanita 53(4):344-349. https://doi.org/10.4415/ANN_17_04_12

118. Koukou MG, Smyrniotis VE, Arkadopoulos NF, Grapsa EI (2017) PD vs HD in post-economic crisis Greece-differences in patient characteristics and estimation of therapy cost. Perit Dial Int 37(5):568-573. https://doi.org/10.3747/pdi.2016.00292

119. Julian-Mauro JC, Cuervo J, Rebollo P, Callejo D (2013) Employment status and indirect costs in patients with renal failure: differences between different modalities of renal replacement therapy. Nefrologia 33(3):333-341. https://doi.org/10.3265/Nefrologia .pre2012.Dec.11767

120. Cortes-Sanabria L, Rodriguez-Arreola BE, Ortiz-Juarez VR, Soto-Molina H, Pazarin-Villasenor L, Martinez-Ramirez HR, Cueto-Manzano AM (2013) Comparison of direct medical costs between automated and continuous ambulatory peritoneal dialysis. Perit Dial Int 33(6):679-686. https://doi.org/10.3747/ pdi.2011.00274

121. Liakopoulos V, Dombros N (2009) Patient selection for automated peritoneal dialysis: for whom, when? Perit Dial Int 29(Suppl 2):S102-107

122. Pecoits-Filho R, Ribeiro SC, Kirk A, da Silva HS, Pille A, Falavinha RS Jr, Filho SS, Figueiredo AE, Barretti P, de Moraes TP (2017) Racial and social disparities in the access to automated peritoneal dialysis-results of a national PD cohort. Sci Rep 7(1):5214. https://doi.org/10.1038/s41598-017-05544-1

123. Szabo E, Moody H, Hamilton T, Ang C, Kovithavongs C, Kjellstrand C (1997) Choice of treatment improves quality of life. A study on patients undergoing dialysis. Arch Intern Med 157(12):1352-1356

Publisher's Note Springer Nature remains neutral with regard to jurisdictional claims in published maps and institutional affiliations. 